\title{
Bicellar systems as new delivery strategy for topical application of flufenamic acid
}

\author{
e1 L. Rubio ${ }^{\mathrm{a}, *}$, C. Alonso a ${ }^{\mathrm{a}}$ G. Rodríguez ${ }^{\mathrm{a}}$, M. Cócera ${ }^{\mathrm{a}}$, C. López-Iglesias ${ }^{\mathrm{b}}$, L. Coderch ${ }^{\mathrm{a}}$, \\ A. De la Maza ${ }^{\mathrm{a}}$, J.L. Parra ${ }^{\mathrm{a}}$, O. López ${ }^{\mathrm{a}}$ \\ a Department of Chemical and Surfactants Technology (IQAC-CSIC), C/Jordi Girona 18-26, 08034 Barcelona, Spain \\ ${ }^{\mathrm{b}}$ Scientific and Technological Centers-University of Barcelona (CCiT-UB), Barcelona Science Park, C/Baldiri Reixac, 10, 08028 Barcelona, Spain
}

\section{A R T I C L E I N F O}

\section{Article history:}

Received 10 October 2012

Received in revised form 14 January 2013

Accepted 17 January 2013

Available online $\mathrm{xxx}$

\section{Keywords:}

Bicellar systems

Flufenamic acid

DSC

ATR-FTIR

SAXS-SR

FS-TEM

In vitro percutaneous absorption

Drug delivery

\begin{abstract}
A B S T R A C T
In this work, bicellar systems, bilayered disc-shaped nanoaggregates formed in water by phospholipids, are proposed as a novel strategy for delivery of the anti-inflammatory flufenamic acid (FFA) to the skin. A comparative percutaneous penetration study of this drug in bicellar systems and other vehicles was conducted. The effects induced on the skin by the application of FFA in the different vehicles were analyzed by attenuated total reflectance-fourier transform infrared (ATR-FTIR). Additionally, using the microscopic technique freeze-substitution transmission electron microscopy (FSTEM) and X-ray scattering technique using synchrotron radiation (SAXS-SR), we studied the possible microstructural and organizational changes that were induced in the stratum corneum (SC) lipids and the collagen of the skin by the application of FFA bicellar systems. Bicellar systems exhibited a retarder effect on the percutaneous absorption of FFA with respect to the other vehicles without promoting disruption in the SC barrier function of the skin. Given that skin disruption is one of the main effects caused by inflammation, prevention of disruption and repair of the skin microstructure should be prioritized in anti-inflammatory formulations.
\end{abstract}

\section{Introduction}

Bicellar systems are mixtures of two types of phospholipids in aqueous medium, one with long alkyl hydrophobic chains and another with short alkyl hydrophobic chains. These phospholipids are able to self-assemble, forming different nanoaggregates. The most common nanostructures formed are discoidal bicelles, which are intermediate forms between lipid vesicles and classical mixed micelles (Sanders and Prosser, 1998; Seddon et al., 2004). Longchain phospholipids constitute the bilayer structure in the central part of the bicelle, and the short-chain phospholipids complete the margins of the disc (Sanders and Schwonek, 1992; Vold and Prosser, 1996). Considering the structure, chemical composition

Abbreviations: SC, stratum corneum; FFA, flufenamic acid; DSC, differential scanning calorimetry; ATR-FTIR, attenuated total reflectance-fourier transform infrared spectroscopy; SAXS-SR, small angle X-ray scattering using synchrotron radiation; FSTEM, freeze-substitution transmission electron microscopy; DPPC, dipalmitoyl phosphatidylcholine; DHPC, dihexanoyl phosphatidylcholine; BSA, bovine serum albumin; PBS, phosphate buffer saline; TEWL, transepidermal water loss; E, epidermis; D, dermis; RF, receptor fluid; Perc. Abs., total percutanous absorption; HEX, hexagonal; OR, orthorhombic; C, corneocytes; L, lipids; $\mathrm{CD}$, corneodesmosomes; DPPC, dimyristoyl phosphatidylcholine; $T_{\mathrm{m}}$, gel-liquid phase transition temperature; SPP, short periodicity phase.

* Corresponding author. Tel.: +34 9340061 00; fax: +34 932045904.

E-mail addresses: laia.rubio@iqac.csic.es, laiarubio@hotmail.com (L. Rubio). (avoiding conventional surfactants) and nanodimensions of bicellar systems, their use as delivery systems for topical applications has emerged as an interesting strategy. The use of bicellar systems has been explored by our group for the transdermal delivery of the amphiphilic drug diclofenac (Rubio et al., 2010). Additionally, we have demonstrated that these systems are able to work for skin applications in two ways: as permeabilizing agents of the skin or as reinforcing agents of the lipid structures of the stratum corneum (SC) (Barbosa-Barros et al., 2008b,c). The skin represents the largest and most easily accessible organ of the body, and it is readily available for drug application. Transdermal drug delivery offers many advantages compared to the conventional routes of application, including avoidance of the first-pass effect, stable blood levels, easy application and higher compliance of the patient (Prausnitz et al., 2004; Thomas and Finnin, 2004) (Bal et al., 2010). To evaluate the passage of substances through the skin and their distribution over the different cutaneous compartments (Elias and Feingold, 2006; OECD, 2004; Schaefer and Redermeier, 1996), in vitro percutaneous absorption studies have been performed to determine the effectiveness of some vehicles as permeability enhancers of different compounds (Gwak and Chun, 2002).

Flufenamic acid (FFA) is a non-steroidal anti-inflammatory drug of the anthranilic acid group with potent anti-inflammatory and analgesic effects (Wagner et al., 2004). This drug, which is commonly included in products for topical application, is insoluble in water, and organic solvents that solubilize this drug could 
62 impair the skin. Given that skin disruption is one of the major 63 proinflammatory stimulators (Rahman et al., 2011), prevention of 64 of primary importance in anti-inflammatory topical formulatio Thus, in these formulations, not only should the drug be effective, but the vehicle must also work in the same way to potentiate the drug effect. Additionally, the deleterious effects of some antiinflammatory molecules themselves on skin structure (Schacke et al., 2002) should be considered and avoided by using appropriate skin-repairing vehicles. In this context, we think that the use of bicellar systems as carriers of FFA may be a good alternative for dermal applications.

Bicellar systems including FFA have been characterized (Rubio et al., 2011) using a combination of different techniques, such as dynamic light scattering (DLS), freeze-fracture electron microscopy (FFEM), cryo-transmission electron microscopy (Cryo-TEM), X-ray scattering and differential scanning calorimetry (DSC). The present study investigates the percutaneous penetration of FFA in different vehicles, as well as the effects induced on the skin by the application of FFA bicellar systems. Attenuated total reflectancefourier transform infrared (ATR-FTIR) spectroscopy, small-angle X-ray scattering (SAXS) using synchrotron radiation (SR) and electron microscopy were used. ATR-FTIR is a suitable technique to determine the vibrational characteristic frequencies of the alkyl chain lipids related to differently ordered phases (Boncheva et al., 2008; Obata et al., 2010; Rodríguez et al., 2009). SAXS is an excellent tool to study the structural organization of the collagen in the skin and the lipid lamellar organization of the SC (Cócera et al., 2011). Freeze-substitution transmission electron microscopy (FSTEM) has been commonly used to visualize the microstructure of the skin (Van den Bergh et al., 1997). In this work, the aforementioned techniques were used to evaluate the microstructure of skin after treatment with FFA bicellar systems in vitro.

\section{Materials and methods}

\subsection{Materials}

Flufenamic acid (FFA) was purchased from Sigma-Aldrich (St. Louis, MO, USA). Dipalmitoyl phosphatidylcholine (DPPC) and dihexanoyl phosphatidylcholine (DHPC) were supplied by Avanti Polar Lipids (Alabaster, AL, USA). Bovine serum albumin (BSA), phosphate-buffered saline (PBS) and gentamicin sulfate were obtained from Sigma-Aldrich. Methanol (HPLC grade), sodium dihydrogen phosphate monohydrate and ortho-phosphoric acid 85\% were acquired from Merck (Darmstadt, Germany). Purified water was obtained by an ultra-pure water system (Milli-Q plus 185, Millipore, Bedford, MA, USA). Ethanol was purchased from Carlo Erba (Milano, Italy). Commercial topical gel containing FFA, salicylic acid and excipients such as isopropanol (Laboratorio Stada, Sant Just Desvern, Spain) was purchased at a local pharmacy. Trypsin (from porcine pancreas) was obtained from Sigma-Aldrich.

The chemicals for preparing microscopy samples were ruthenium tetroxide $\left(\mathrm{RuO}_{4}\right)$, lowicryl HM20, glutaraldehyde, sodium cacodylate buffer (Electron Microscopy Sciences, Hatfield, PA, USA), methanol, potassium ferrocyanide $\left(\mathrm{K}_{4} \mathrm{Fe}(\mathrm{CN})_{6}\right)$ (Merck), and osmium tetroxide $\left(\mathrm{OsO}_{4}\right)$ (Pelco International, Redding, $\mathrm{CA}$, USA).

\subsection{Methods}

\subsubsection{Preparation of bicellar systems}

Bicellar systems including FFA were formed with DPPC as the long-alkyl-chain phospholipid and DHPC as the short-alkyl-chain phospholipid. An appropriate amount of DPPC was weighed and mixed with a DHPC/chloroform solution to yield DPPC/DHPC in the molar ratio 2:1. $10 \mathrm{mg}$ of FFA was weighed and mixed with the DPPC/DHPC chloroformic solution. The chloroform was removed by rota-evaporation, and the lipid film was dissolved in $1 \mathrm{ml}$ of water to reach a $20 \%(\mathrm{w} / \mathrm{v})$ total lipid concentration and sonicated until a transparent solution was obtained. pH measurements of FFA bicellar systems were performed with a Model $720 \mathrm{pH}$ meter and a ROSS Model 8103 SC pH electrode (both from Orion Research, Cambridge, MA, USA).

\subsubsection{HPLC analysis}

FFA was quantified by high-performance liquid chromatography (HPLC) using a Hitachi LaChrom Elite (Darmstadt, Germany). The equipment consisted of an L-2130 pump, L-2200 autosampler and L-400 UV detector. The system was operated using the Merck EZChrom Elite v3.1.3 software. The chromatographic separation was performed at room temperature using a Lichrocart 250-4/Lichrosorb RP-18 (5 $\mu \mathrm{m})$ column (Merck) with a flow rate of $1.0 \mathrm{ml} / \mathrm{min}$. $20 \mu \mathrm{l}$ of sample or calibration standard was injected into the column and eluted with a mobile phase of methanol and phosphate buffer ( $\mathrm{pH} 2.5$ ) (79:21, v/v). Detection was performed by monitoring the absorbance signals at $284 \mathrm{~nm}$. The calibration curve exhibited linear behavior $(>0.99 \%)$ over the concentration range of $0.078-97 \mu \mathrm{g} / \mathrm{ml}$. The intraday and interday variations of the method were less than $2 \%$.

\subsubsection{In vitro percutaneous absorption studies}

The in vitro permeation experiments through porcine skin were performed using Franz-type diffusion cells with an exposure area of $1.86 \mathrm{~cm}^{2}$ (Lara-Spiral, Courtenon, France). The porcine skin was excised from the dorsal region of female Landrace large white pigs weighing $30-40 \mathrm{~kg}$. The pig skin was provided by the Clinical Hospital of Barcelona, Spain. The bristles were removed carefully with an animal clipper, and subsequently, the skin was washed with water. The excised skin was dermatomed to a thickness of $500 \pm 50 \mu \mathrm{m}$ (Dermatome GA630, Aesculap, Tuttlingen, Germany). Circular pieces of the dermatomed skin were obtained using an iron punch $(2.5 \mathrm{~cm}$ inner diameter $)$ in such a way that they fit into the Franz diffusion cells. The skin discs were stored at $-20^{\circ} \mathrm{C}$.

Before the experiments, the skin discs were thawed and sandwiched securely between the two halves of the Franz cells (diffusion area of $1.86 \mathrm{~cm}^{2}$ ) with the SC side facing the donor compartment. The receptor chamber was filled with a receptor fluid containing PBS (pH 7.4) in distilled water, $4 \%$ BSA, and $0.04 \%$ of gentamicin sulfate.

The receptor phase was kept under constant stirring at $37 \pm 1{ }^{\circ} \mathrm{C}$ by means of a circulating water bath (Julabo Labortechnik $\mathrm{GmbH}$, Germany) to ensure that the surface skin was maintained at $32 \pm 1{ }^{\circ} \mathrm{C}$. The integrity of each skin sample was measured by determining the transepidermal water loss (TEWL) using a Tewameter TM210 (Courage-Khazaka, Köln, Germany). The diffusion experiment was initiated by applying each formulation to the entire surface, delimited by the upper cell, $10 \mu$ l of each of the ethanolic or bicellar solution of FFA and approximately $4 \mathrm{mg}$ of the commercial product of FFA. The doses applied were based on the OCDE recommendations (OECD, 2004). The permeation experiments were conducted in six replicates over $24 \mathrm{~h}$. After $24 \mathrm{~h}$, the content of the donor compartment was washed with sodium lauryl ether sulfate and Milli-Q water following usual procedures, and the washing solution was collected. Then, the receptor fluid was removed from the receptor compartment and brought up to $5 \mathrm{ml}$ in a volumetric flask. Most of the SC of the treated skin area was removed by 8 successive tape-strippings using an adhesive tape (D-Squame ${ }^{\circledR}$, CuDerm Inc., Dallas, USA). After that, the viable epidermis (E) was separated from the dermis (D) by heat treatment at $80^{\circ} \mathrm{C}$ for a few seconds. 
The FFA in the washing solution and in the different skin layers (SC, E, and D) was extracted with methanol overnight. The different extracted samples and the receptor fluid were filtered through a $0.45 \mu \mathrm{m}$ Acrodisc filter (Pall Gelman Sciences, Northampton, UK) and analyzed by HPLC as described above.

\subsubsection{ATR-FTIR spectroscopy}

Four circular pieces of porcine skin were placed in Franz diffusion cells as above. Three of them were treated with $10 \mu$ l of FFA ethanolic solution, FFA bicellar systems or approximately $10 \mathrm{mg}$ of FFA commercial product, respectively. The other sample was used as a control (untreated). The skin exposure lasted $24 \mathrm{~h}$; after that, the skin was washed with sodium lauryl ether sulfate and Milli-Q water and removed from the diffusion cells.

Infrared spectra of the porcine skin samples were obtained using a 360-FTIR spectrophotometer Nicolet Avatar (Nicolet Instruments, Inc., Madison, WI) equipped with an attenuated total reflection (ATR) accessory that used a ZnSe crystal with an angle of incidence of $45^{\circ}$ in a horizontal orientation.

Before analysis, the skin was placed with the SC facing onto the ZnSe ATR crystal. To ensure reproducible contact between the sample and the crystal, a pressure of $10 \mathrm{kPa}$ was applied to the samples. The IR spectra were collected at $25^{\circ} \mathrm{C}, 32.5^{\circ} \mathrm{C}$ and $37^{\circ} \mathrm{C}$. These three temperatures were chosen because $25^{\circ} \mathrm{C}$ is room temperature, $32.5^{\circ} \mathrm{C}$ is approximately the temperature of the skin surface, and $37^{\circ} \mathrm{C}$ is the physiological body temperature. To ensure equilibration of the temperature, the skin samples were placed in the equipment $30 \mathrm{~min}$ before collecting the spectra. The temperature was controlled by a temperature controller integrated into the ATR device and by an external thermostatic jacket.

All analyzed spectra represented an average of 256 scans obtained in $7 \mathrm{~min}$ with a resolution of $2 \mathrm{~cm}^{-1}$, and the wavenumber range used was $4000-700 \mathrm{~cm}^{-1}$. Peak positions were determined with the aid of OMNIC software version 7.3 (Nicolet, Madison, WI).

\subsubsection{Freeze-substitution transmission electron microscopy (FSTEM)}

Two porcine skin discs, one control and one treated with FFA bicellar systems, were processed as for percutaneous absorption studies. Then, the porcine skin samples were cut into small rectangular pieces with a size of approximately $2 \mathrm{~mm} \times 1 \mathrm{~mm}$. The pieces were fixed with $5 \%(\mathrm{w} / \mathrm{v})$ glutaraldehyde buffered with $0.1 \mathrm{M}$ sodium cacodylate ( $\mathrm{pH} 7.2$ ). The postfixation was performed using $0.2 \%(\mathrm{w} / \mathrm{v}) \mathrm{RuO}_{4}$ in sodium cacodylate buffer $(\mathrm{pH}$ $6.8)$ with $0.25 \%(\mathrm{w} / \mathrm{v}) \mathrm{K}_{4} \mathrm{Fe}(\mathrm{CN})_{6}$ for $1 \mathrm{~h}$. After rinsing in buffer and prior to freeze-substitution, the tissue samples were cryofixed in liquid nitrogen $\left(-196^{\circ} \mathrm{C}\right)$ using a Cryovacublock (Leica, Vienna). The freeze-substitution method was implemented using an Automatic Freeze Substitution (AFS) system (Leica Microsystems, Vienna, Austria). The freeze-substitution fluid consisted of $1.0 \%(\mathrm{w} / \mathrm{v}) \mathrm{OsO}_{4}, 0.5 \%(\mathrm{w} / \mathrm{v})$ uranyl acetate and $3.0 \%(\mathrm{w} / \mathrm{v})$ glutaraldehyde in methanol. The tissue samples were cryosubstituted at $-90^{\circ} \mathrm{C}$ for $48 \mathrm{~h}$. After the substitution period, the temperature was raised to $-50^{\circ} \mathrm{C}$, and the samples were washed 3 times in $100 \%$ methanol. After that, the methanol solution was gradually replaced by the embedding medium, Lowicryl HM20 (100\%). This resin was replaced after 24 and again after $48 \mathrm{~h}$ by freshly prepared embedding medium. Finally, the samples were transferred to a mold containing Lowicryl and were incubated for $48 \mathrm{~h}$ at $-50^{\circ} \mathrm{C}$ under UVA irradiation to allow polymerization. Ultrathin sections were prepared on an ultramicrotome (Ultracut UCT, Leica, Vienna, Austria), transferred to Formvar-coated grids and examined using a Hitachi 600 transmission electron microscope.

\subsubsection{X-ray scattering measurements}

2.2.6.1. Whole dermatomed skin. The SAXS profile of control skin and skin treated with FFA bicellar systems as described in the percutaneous absorption section were analyzed to characterize the organization of the collagen of the skin. SAXS measurements were performed using the Spanish beamline (BM16) of the European Synchrotron Radiation Facility (ESRF, Grenoble, France) at room temperature. All of these skin samples were cut into sections $1 \mathrm{~mm}$ thick and $10 \mathrm{~mm}$ in diameter and were placed in the holder with the skin surface perpendicular to the beam. In the holder, skin pieces were sandwiched between two aluminum plates with two holes, allowing the beam to pass directly through the samples. The energy of the beam was $12 \mathrm{keV}(\lambda=0.9795 \AA)$. The scattering data were collected with a SAXS 2D detector MARCCD (Marresearch GmbH, Norderstedt, Germany) with an active surface area with a diameter of $165 \mathrm{~mm}$ (Rueda et al., 2006) and a single exposure time of approximately $60 \mathrm{~s}$. The sample-to-detector distance of $5 \mathrm{~m}$ (long set-up) was used. Calibration was performed using silver behenate. Spacing was determined from axially integrated 2D images using the FIT2D program (http://www.esrf.eu/computing/scientific/FIT2D) from ESRF. The data were normalized with transmitted intensity.

2.2.6.2. Isolated SC. A control skin and a skin treated with FFA bicellar systems for $24 \mathrm{~h}$ were heated with the SC side in contact with a metal plate for $10 \mathrm{~s}$ at $80^{\circ} \mathrm{C}$, and the epidermis was scraped off in sheets. To isolate the SC, the epidermal sheets were incubated for $2 \mathrm{~h}$ at $37^{\circ} \mathrm{C}$ with the epidermal side in contact with a solution of $0.5 \%$ trypsin in PBS (pH 7.4). Trypsin was used to remove adherent cells from epidermis. After the $2 \mathrm{~h}$, the trypsin was removed by several washes of the SC with Milli-Q water.

SAXS measurements of the isolated SC were performed using the same technical specifications as for whole skin but changing the sample-to-detector distance to $1.4 \mathrm{~m}$ (short set-up) to achieve a $q$ range between 0.2 and $2 \mathrm{~nm}^{-1}$.

The SAXS technique provides information about the larger structural units in the sample, namely, the repeat distance of one structure (collagen for whole dermatomed skin and lipid lamellar structure for isolated SC). The scattering intensity ( $I$, in arbitrary units) was measured as a function of the scattering vector $q$ (in $\mathrm{nm}^{-1}$ ), with a modulus defined as:

$q=\frac{4 \pi \sin \theta}{\lambda}$

where $\theta$ is the scattering angle and $\lambda$ the wavelength of the radiation $(0.9795 \AA)$. The position of the diffraction peaks is directly related to the repeat distance of the molecular structure, as described by Bragg's law (Bragg, 1913):

$2 d \sin \theta=n \lambda$

where $n$ and $d$ are the order of the diffraction peak and the repeat distance, respectively. The different orders of peaks are calculated by:

$q_{n}=\frac{2 \pi n}{d}$

where $q_{n}$ is the scattering vector modulus that indicates the position of the $n$ th-order reflection.

\subsubsection{Statistical analysis}

Percutaneous absorption values are expressed as the mean \pm standard deviation (SD) of six determinations. For group comparisons, analysis of variance (ANOVA) with a one-way layout was applied. The software used was STATGRAPHICS plus 5. Significant differences in the mean values were evaluated using the Student's unpaired t-test. A $p$ value of less than 0.05 was 


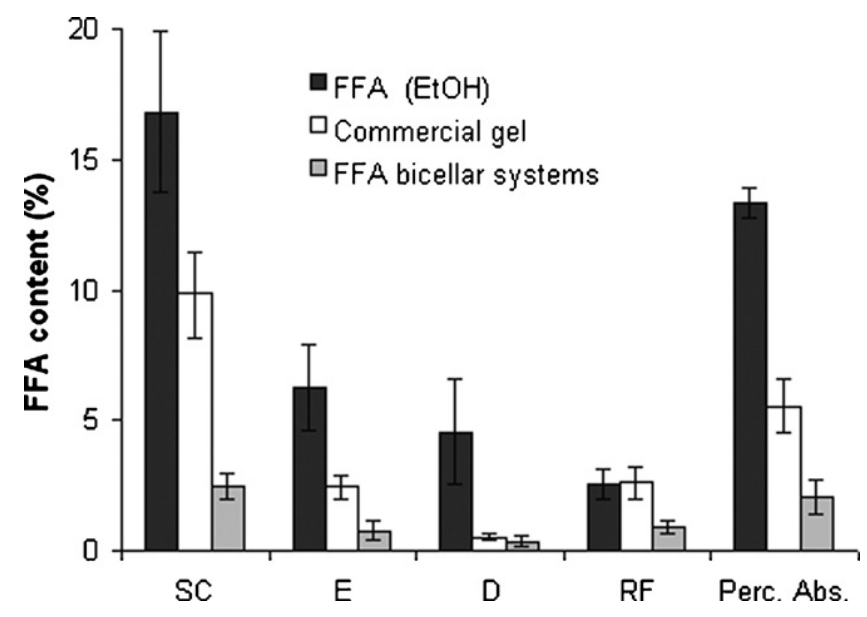

Fig. 1. Distribution of FFA content after $24 \mathrm{~h}$ of exposure. Amounts detected in the stratum corneum (SC), epidermis (E), dermis (D), receptor fluid (RF) and the total percutaneous absorption (Perc. Abs.). Bars are the \% of applied dose (mean of $n=6$ ), and the errors bars are the standard deviations (S.D.).

considered significant. The positions of IR peaks were obtained as the mean values \pm SD of three measurements.

\section{Results}

Visual inspection of FFA bicellar systems showed differences in the appearance depending on the temperature. At $25^{\circ} \mathrm{C}$ the systems exhibited a milky appearance, at $32.5^{\circ} \mathrm{C}$ the sample was fluid and completely transparent, and at $37^{\circ} \mathrm{C}$, it became translucent. No precipitates were observed in the bicellar systems at any of these temperatures. The pH of the FFA bicellar system was approximately 5.5. Thus, bicellar systems are an appropriate vehicle to use in topical applications because under normal conditions the skin has a pH between 4 and 5.5 (Parra and Paye, 2003).

\subsection{In vitro percutaneous studies}

HPLC analysis showed that in all three cases, the extraction efficiency of FFA from the different skin layers, washing solution and receptor fluid was higher than $97 \%$. The highest amount of FFA remained on the skin surface after application using all the vehicles. This effect was especially noted in the case of FFA bicellar systems, in which $94.5 \pm 1.7 \%$ of the total amount applied was removed as surface excess. FFA in ethanol showed the lowest value, $67.2 \pm 4.6 \%$, and the commercial product showed an intermediate value $(83.0 \pm 5.4 \%)$. The three cases were significantly different from each other. Fig. 1 shows the percutaneous absorption profiles of FFA vehiculized in bicellar systems compared with FFA in an ethanolic solution (1\%) and with the commercial product after $24 \mathrm{~h}$ of exposure. The results are expressed as a percentage of FFA in each compartment investigated with respect to the dose applied to the skin.

It is interesting to note that among all the skin layers, a higher percentage of FFA in the SC was detected for the three formulations. This behavior was noted especially when the drug was applied in the ethanolic solution $(16.8 \pm 3.1 \%)$. The lower content of FFA in the SC corresponded to that applied in bicellar systems $(2.5 \pm 0.5 \%)$. These data indicate a smaller SC reservoir when the drug was included in bicellar systems. The SC reservoir is the amount of material in this layer that is available for further absorption (Schaefer and Redermeier, 1996). When the commercial product was used, the value of FFA content in SC was in between the two previous cases $(9.8 \pm 1.7 \%)$.
In the epidermis (E), the tendency was the same as in the SC showing statistically significant differences between all the cases. However, in the dermis (D), the content of FFA for the ethanolic solution was greater than in the other vehicles, and there were no significant differences between the content of FFA in the dermis with bicellar systems and the commercial product. Observing the receptor fluid (RF) results, in the cases of the commercial product and the ethanolic solution, the content of FFA was similar (about $2.6 \%$ ), but significantly less drug was detected in the RF with the bicellar systems $(0.9 \pm 0.2 \%)$.

The global percentage of percutaneous absorption (considering the amount of FFA detected in E plus D plus RF) showed significant differences in the absorption of FFA when different vehicles were used. Considering all the skin layers, the total percutaneous absorption of FFA was greater when the drug was included in ethanol or in the commercial formulation than when the drug was included in the bicellar systems.

\subsection{ATR-FTIR spectroscopy}

ATR-FTIR is a noninvasive spectroscopic technique whereby the sample is placed directly onto an ATR crystal. This technique is useful to investigate the $\mathrm{SC}$ without isolation from the other skin layers. This is because the depth of penetration of the radiation into the skin is approximately $1 \mu \mathrm{m}$ (Coderch et al., 1999). Previous works reported IR spectra of porcine skin in vitro (Boncheva et al., 2008; Rodríguez et al., 2009; Rodriguez et al., 2010) showing the vibrational characteristic frequencies of the alkyl chain lipids related to differently ordered phases of the SC. In the present work, we investigated the effect of the different systems containing FFA on the SC lipids.

The control skin and the skin treated with FFA in the different vehicles were analyzed at $25,32.5$ and $37^{\circ} \mathrm{C}$. The spectrum analysis focused on bands associated with the alkyl chain of SC lipid vibrations as follows: $\mathrm{CH}_{2}$ stretching (around 2920 and $2850 \mathrm{~cm}^{-1}$ ) and $\mathrm{CH}_{2}$ scissoring (between 1480 and $1460 \mathrm{~cm}^{-1}$ ).

\subsection{1. $\mathrm{CH}_{2}$ stretching region}

The methylene stretching vibrations (between 2800 and $\left.3000 \mathrm{~cm}^{-1}\right)$ provide information on the conformation ordering (e.g., gel or liquid crystalline) of the SC lipid alkyl chains (Boncheva et al., 2008; Rodríguez et al., 2009). In our ATR-FTIR spectra and in accordance with other authors (Gooris and Bouwstra, 2007; Prasch et al., 2000), the asymmetric and the symmetric $\mathrm{CH}_{2}$ stretching vibrations were observed near 2920 and $2850 \mathrm{~cm}^{-1}$, respectively. In all spectra obtained for all the skin samples, both modes were intense and did not overlap with other vibrational modes in this region. Tables 1 and 2 show the values obtained for the symmetric and asymmetric stretching modes, respectively, for the control skin and for the skin treated with FFA in the different vehicles at the three different temperatures. In the case of the symmetric $\mathrm{CH}_{2}$ stretching, a vibrational frequency of $2849 \mathrm{~cm}^{-1}$ indicates an orthorhombic chain conformation, of $2850 \mathrm{~cm}^{-1}$ a hexagonal chain conformation and of $2852 \mathrm{~cm}^{-1}$ a liquid crystalline chain conformation (Rodríguez et al., 2009). An increase of the vibrational frequency indicates an increase of the disordering. The same occurs with the $\mathrm{CH}_{2}$ asymmetric stretching: an increase of vibrational frequency denotes a disordering.

Concerning the symmetric mode (Table 1 ), in the control skin, a small increase of the $\mathrm{CH}_{2}$ stretching frequency $(2850.1 \pm 0.6$ to $2850.8 \pm 0.2 \mathrm{~cm}^{-1}$ ) was observed when the temperature increased from 25 to $37^{\circ} \mathrm{C}$. These results are compatible with a hexagonal (HEX) packing lattice with a tendency to increase the disorder packing, in agreement with results published by other authors (Furuishi et al., 2010; Pensack et al., 2006; Rodríguez et al., 2009; Rodriguez et al., 2010). The skin treated with FFA bicellar systems at $25^{\circ} \mathrm{C}$ 
Table 1

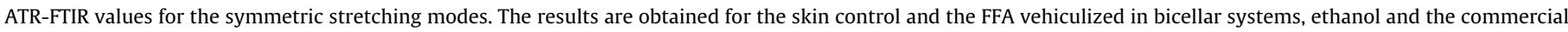
product.

\begin{tabular}{|c|c|c|c|c|}
\hline \multirow[t]{2}{*}{ Temperature $\left({ }^{\circ} \mathrm{C}\right)$} & \multicolumn{4}{|c|}{ Symmetric stretching band $\left(\mathrm{cm}^{-1}\right)^{a}$} \\
\hline & Skin control & Skin + Bice FFA & Skin + FFA (EtOH) & Skin + FFA commerc. \\
\hline 25 & $2850.1 \pm 0.6$ & $2849.2 \pm 0.3$ & $2850.0 \pm 0.2$ & $2849.3 \pm 0.2$ \\
\hline 32.5 & $2850.6 \pm 0.0$ & $2849.8 \pm 0.2$ & $2850.2 \pm 0.8$ & $2849.9 \pm 0.0$ \\
\hline 37 & $2850.8 \pm 0.2$ & $2850.5 \pm 0.9$ & $2850.3 \pm 0.1$ & $2850.2 \pm 0.2$ \\
\hline
\end{tabular}

a Values represents the mean \pm S.D. of three measurements.

showed a vibrational band for $\mathrm{CH}_{2}$ at $2849.2 \pm 0.3 \mathrm{~cm}^{-1}$, corresponding to an orthorhombic (OR) phase. This result indicates a major ordering of the SC lipids in the sample treated with the FFA bicellar systems compared to the control sample. The increase of temperature induced an increase of the $\mathrm{CH}_{2}$ symmetric stretching frequency from $2849.2 \mathrm{~cm}^{-1}$ at $25^{\circ} \mathrm{C}$ to $2850.5 \mathrm{~cm}^{-1}$ at $37{ }^{\circ} \mathrm{C}$, indicating a transition from the OR to HEX phase. This result agrees with those reported by Rodriguez et al. (2010), who applied DPPC/DHPC bicelles to porcine skin, although those systems did not contain FFA.

When the ethanolic solution of FFA was applied to the porcine skin the $\mathrm{CH}_{2}$ symmetric stretching frequency remained practically unaltered compared to the control. This frequency did not change much with the increase of temperature (from $2850.0 \pm 0.2$ to $2850.3 \pm 0.1 \mathrm{~cm}^{-1}$ ) corresponding in all cases to a HEX phase (Boncheva et al., 2008; Rodriguez et al., 2010). The results obtained from the application of the FFA commercial product show a transition from an OR phase to a HEX phase with the increase of temperature. This transition was also detected in the case of FFA bicellar systems.

Although the stretching symmetric vibrations of $\mathrm{CH}_{2}$ are more sensitive than the asymmetric vibrations to packing changes (Mendelsohn et al., 2006) the latter have been used in some studies for similar purposes (Coderch et al., 1999; Rodríguez et al., 2009). Table 2 shows the values detected for the $\mathrm{CH}_{2}$ asymmetric stretching mode. Concerning the control skin, from 25 to $32.5^{\circ} \mathrm{C}$, the frequency remained unaltered (from $2920.1 \pm 0.5$ to $2920.2 \pm 0.4 \mathrm{~cm}^{-1}$ ), but when the temperature increased to $37^{\circ} \mathrm{C}$, a change to higher values of frequency $\left(2922.1 \pm 0.5 \mathrm{~cm}^{-1}\right)$ was observed, indicating a higher fluidity of the SC lipids at this temperature. In the case of the skin treated with FFA bicellar systems, the $\mathrm{CH}_{2}$ asymmetric stretching frequency at $25^{\circ} \mathrm{C}$ was $2917.1 \pm 0.2 \mathrm{~cm}^{-1}$, quite below that detected in the control skin, indicating that treatment with FFA bicellar systems induces an ordering in the SC lipid lattice. When the temperature increased to $32.5^{\circ} \mathrm{C}$, the frequency was maintained, but at $37^{\circ} \mathrm{C}$, this value increased to $2919.9 \pm 0.3 \mathrm{~cm}^{-1}$, suggesting that the lipid fluidization increases when the temperature increases. In the case of the skin treated with FFA ethanolic solution, at $25^{\circ} \mathrm{C}$, the frequency was $2917.3 \pm 0.5 \mathrm{~cm}^{-1}$, at $32.5^{\circ} \mathrm{C}$, the frequency increased to $2918.3 \pm 0.2 \mathrm{~cm}^{-1}$, and at $37^{\circ} \mathrm{C}$, the frequency remained at this higher level. Increased disordering was observed when the temperature increased from 25 to $32.5^{\circ} \mathrm{C}$. When the porcine skin was treated with the FFA commercial solution, an increase of the disordering was noted when the temperature changed from $25^{\circ} \mathrm{C}$ $\left(2918.5 \pm 0.5 \mathrm{~cm}^{-1}\right)$ to $32.5^{\circ} \mathrm{C}\left(2920.1 \pm 0.7 \mathrm{~cm}^{-1}\right)$. At $37^{\circ} \mathrm{C}$, the increase was slightly smaller $\left(2920.3 \pm 0.8 \mathrm{~cm}^{-1}\right)$.

In summary, FFA bicellar systems and the FFA commercial product induced an ordering of the SC lipids compared to the control. This change occurred in both the symmetric and the asymmetric stretching vibrations. When FFA was applied with the ethanolic solution, the symmetric stretching band indicated no alteration of the ordering of the SC lipids compared to the control, nor did temperature affect the ordering. A shift of the asymmetric stretching band in the ethanolic treatment was observed, indicating an ordering of the SC lipids at all the temperatures compared to the control skin.

\subsection{2. $\mathrm{CH}_{2}$ scissoring region}

The scissoring vibrations provide information on the lateral packing properties of the SC lipids. A single methylene band at $\sim 1468 \mathrm{~cm}^{-1}$ represents HEX acyl chain packing of the lipids, whereas OR chain packing is indicated by two components at $\sim 1472 \mathrm{~cm}^{-1}$ and $\sim 1464 \mathrm{~cm}^{-1}$ (Kaushik and Michniak-Kohn, 2010). In the range of the $\mathrm{CH}_{2}$ scissoring region (1480-1460 $\left.\mathrm{cm}^{-1}\right), \mathrm{CH}_{3}$ bending modes associated mostly with the skin keratins also occur (Boncheva et al., 2008). Because the scissoring region range is small, this region was enlarged to facilitate the analysis of the significant peaks (Fig. 2). To help in the identification of the peaks, Gaussian deconvolution and curve fitting were used. In Fig. 2, the curve fitting and the Gaussian bands of the scissoring region of the control skin and skins treated with FFA bicellar systems, FFA ethanolic solution or the commercial product at $37^{\circ} \mathrm{C}$ are shown. At the other temperatures studied, similar bands were obtained as at $37^{\circ} \mathrm{C}$.

The curve fitting of the control sample at $37^{\circ} \mathrm{C}$ (Fig. 2A) indicated two Gaussian bands, at 1467.5 and $1471.0 \mathrm{~cm}^{-1}$. The vibrational band centered at $1467.5 \mathrm{~cm}^{-1}$ was compatible with a HEX lipid organization, and that detected at $1471.0 \mathrm{~cm}^{-1}$ was compatible with a distorted OR packing, corresponding to one of the bands of the characteristic OR symmetry split. The fitting curve for skin treated with FFA bicellar systems (Fig. 2B) showed three Gaussian bands centered at $1462.6,1468.3$ and $1471.4 \mathrm{~cm}^{-1}$, respectively. The bands centered at 1462.6 and $1471.4 \mathrm{~cm}^{-1}$ could correspond to the split characteristic of OR packing, and the vibrational band at around $1468 \mathrm{~cm}^{-1}$ was characteristic of a HEX phase. In the case of the skin treated with FFA ethanolic solution (Fig. 2C), two bands centered at 1465.7 and $1471.5 \mathrm{~cm}^{-1}$ were observed. The band at around $1466 \mathrm{~cm}^{-1}$ could have been due to a shift of the HEX packing band, and the vibration at $1471.5 \mathrm{~cm}^{-1}$ could correspond to

Table 2

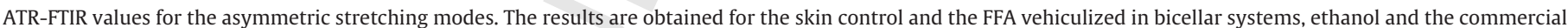
product.

\begin{tabular}{|c|c|c|c|c|}
\hline \multirow[t]{2}{*}{ Temperature $\left({ }^{\circ} \mathrm{C}\right)$} & \multicolumn{4}{|c|}{ Asymmetric stretching band $\left(\mathrm{cm}^{-1}\right)^{\mathrm{a}}$} \\
\hline & Skin control & Skin + Bice FFA & Skin + FFA (EtOH) & Skin + FFA commerc. \\
\hline 25 & $2920.1 \pm 0.5$ & $2917.1 \pm 0.2$ & $2917.3 \pm 0.5$ & $2918.5 \pm 0.5$ \\
\hline 32.5 & $2920.2 \pm 0.4$ & $2917.0 \pm 0.8$ & $2918.3 \pm 0.2$ & $2920.1 \pm 0.7$ \\
\hline 37 & $2922.1 \pm 1.4$ & $2919.9 \pm 0.3$ & $2918.2 \pm 0.3$ & $2920.3 \pm 0.8$ \\
\hline
\end{tabular}

\footnotetext{
a Values represents the mean \pm S.D. of three measurements.
} 

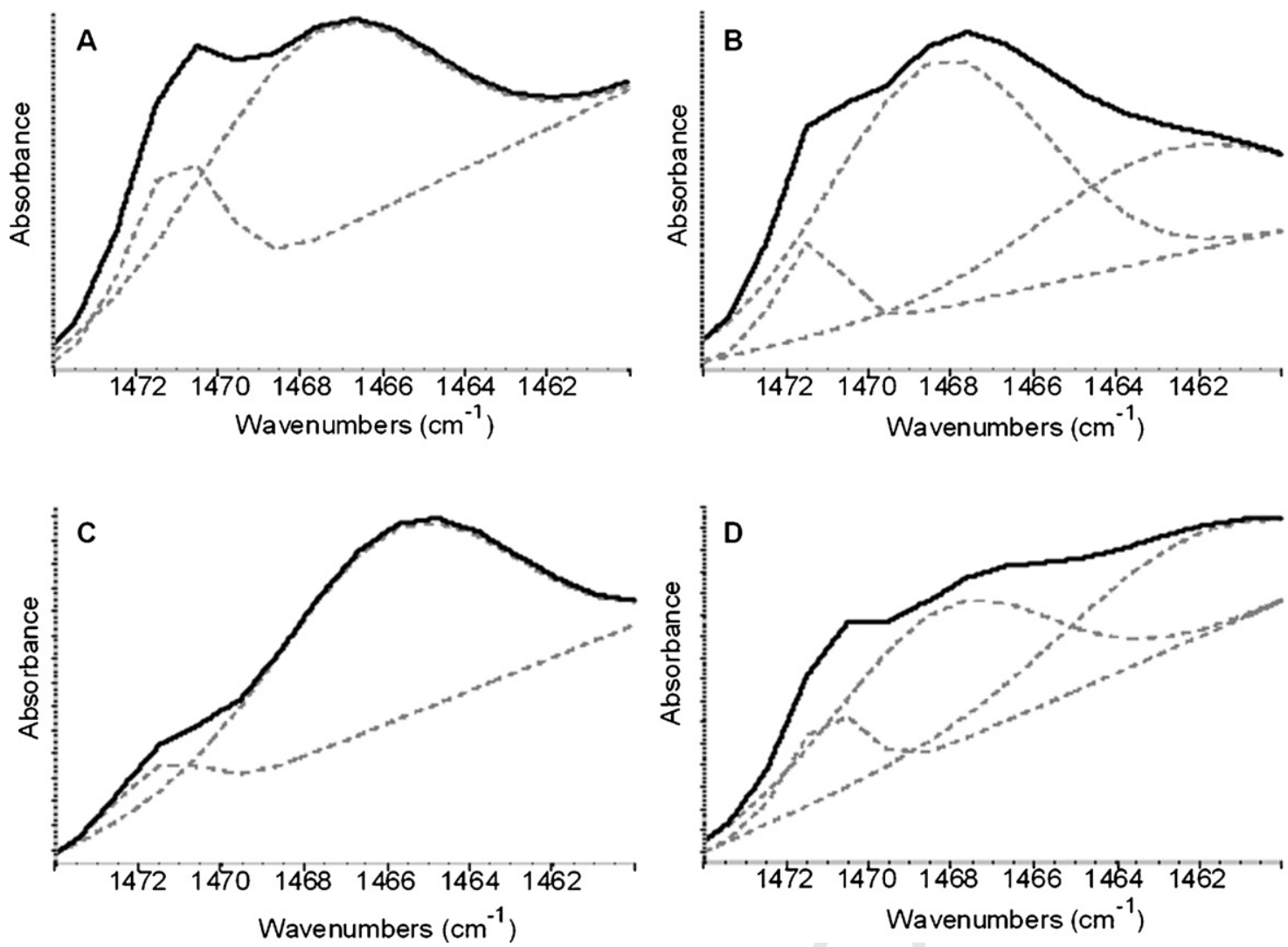

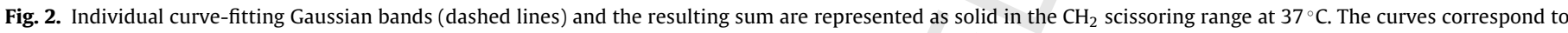
control skin (A), skin treated with FFA bicellar systems (B), FFA ethanolic solution (C) and FFA commercial product (D).

one of the vibrations characteristic of the split of the OR packing. Fig. 2D shows Gaussian bands in the scissoring range of the skin treated with the commercial product. Three vibrational bands centered at $1462.1,1468.2$ and $1471.0 \mathrm{~cm}^{-1}$ are shown. As in the other cases, the band centered at around $1468 \mathrm{~cm}^{-1}$ was characteristic of a HEX lattice. The other two bands could correspond to a splitting characteristic of an OR packing or could have been due to the $\mathrm{CH}_{3}$ bending modes.

\subsection{FSTEM}

To evaluate the effect of FFA bicellar systems on the microstructure of SC, we visualized the native tissue and the skin treated with FFA bicellar systems, micrographs of which are shown in Figs. 3 and 4, respectively. Fig. 3A depicts an overview of the SC, where skin corneocytes (C), flattened cells characterized by the absence of a nucleus or cytoplasmic organelles and the presence of keratin filaments are clearly visualized. Additionally, in the intercellular spaces, lipid bilayers (L) and corneodesmosomes (CD), which are SC desmosomes representing the contact areas between adjacent corneocytes, are visible. Fig. 3B shows an enhanced micrograph of the intercellular lipids. In the intercellular space, lipids (L) are observed as regularly packed multilayered structures. Micrographs from Fig. 4 show SC from skin treated with FFA bicellar systems. Fig. 4A depicts an overview, whereas Fig. 4B shows a detailed intercellular space. Similar to control skin, Fig. 4 shows that skin corneocytes (C), corneodesmosomes (CD) and, in the intercellular spaces, the lipid lamellae (L) were also clearly visualized. No differences were observed in the different areas of SC after treatment with FFA bicellar systems in comparison to native tissue. This fact indicates that the treatment with these systems did not induce apparent microstructural changes in the SC organization.

\subsection{X-ray scattering results}

\subsubsection{Dermatomed whole skin}

Fig. 5 shows the 1D scattering patterns from control skin and skin treated with FFA bicellar systems resulting from the average of several images after integration with FIT2D software. The dermatomed skin samples had a dermis thickness of approximately $400 \mu \mathrm{m}$. The profiles of both samples show the characteristic peaks of the typical scattering pattern of collagen. In both cases, the characteristic peak centered at $q \approx 0.1 \mathrm{~nm}^{-1}$, corresponding to a d-spacing around $63 \mathrm{~nm}$, which is associated with the axial periodicity of collagen (Cócera et al., 2011) (marked region), and their reflections are clearly visualized. The typical axial periodicity of collagen is the result of the displacement of each molecule in a particular direction with respect to the adjacent molecules (Cócera et al., 2011).

At low q, differences in the intensity between both samples were observed. In Fig. 6, a magnification of the SAXS profiles at low $q$ (gray area in Fig. 5) has been plotted to elucidate these differences.

Fig. 6 shows the experimental and fitted curves of the SAXS profile of the control skin and the skin treated with FFA bicellar systems at low q. Differences in the intensity and number of bands between these two samples were observed. The curves were fitted to two (control skin) or three (skin treated) Gaussian bands using Origin software. The resulting bands for control skin were centered at $q$ around 0.055 and $0.099 \mathrm{~nm}^{-1}$, corresponding to a d-spacing around 114 and $63 \mathrm{~nm}$, respectively. For treated skin, the resulting bands were centered at $q$ around $0.054,0.075$ and $0.098 \mathrm{~nm}^{-1}$, corresponding to spacings of around 116,84 , and $64 \mathrm{~nm}$, respectively. Mérigoux and co-workers (Mérigoux et al., 1997) found similar spacings in their study of the skin, which were associated with the axial $(65 \mathrm{~nm})$ or lateral packing of collagen fibrils $(115 \mathrm{~nm})$ and the 

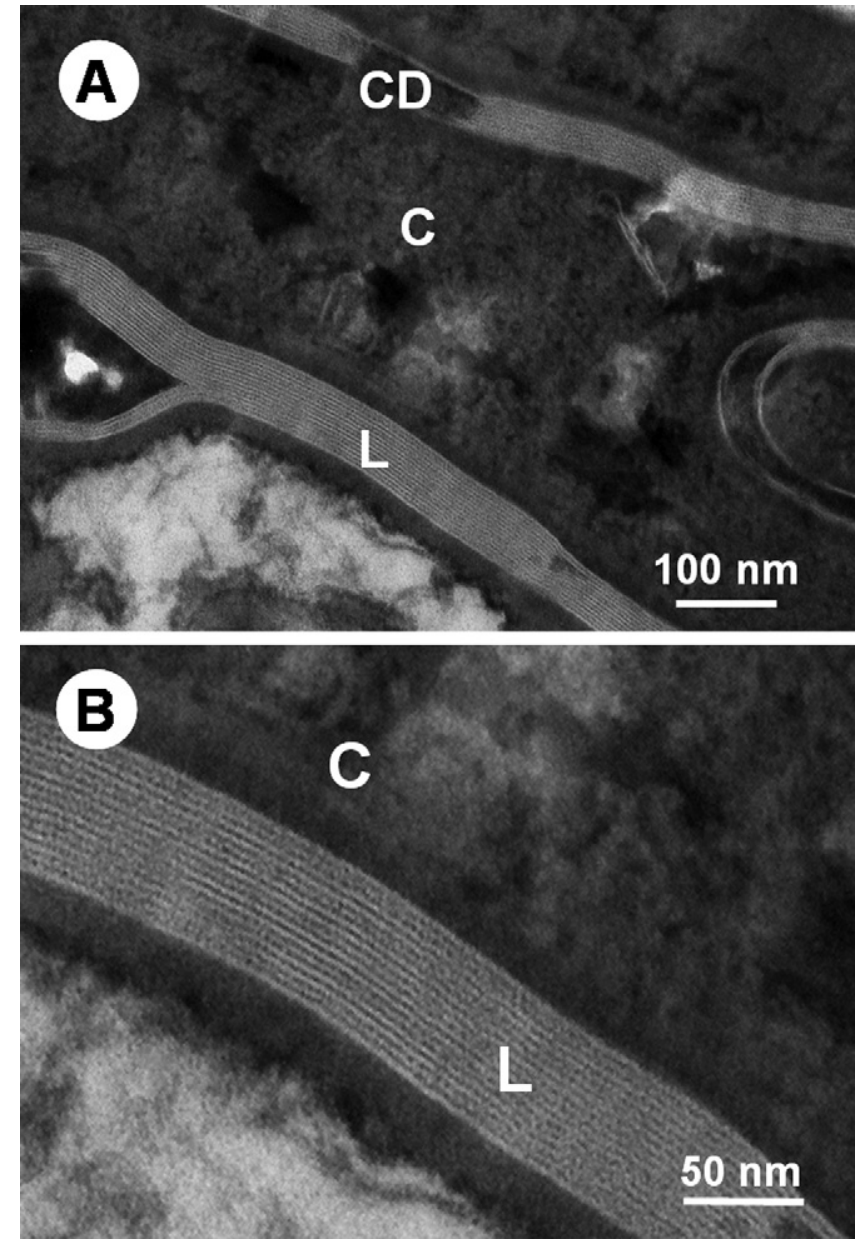

Fig. 3. FSTEM micrographs of SC from control skin. Picture A: overview of the SC. Picture B: detailed micrograph of the lamellar structure. Symbols: corneocytes (C), corneodesmosomes (CD) and lipids (L).

scattering from the cylindrical shape of the fibrils ( $85 \mathrm{~nm}$ ) in skin collagen. Thus, reflections detected in our experiments were probably associated with the organization of skin collagen. Modification of the collagen scattering pattern after treatment with the bicellar system including FFA is indicative of the ability of the system to reach the dermis, where collagen is located. Differences between scattering patterns in both samples could be attributed to an effect of the anti-inflammatory molecules on the collagen arrangement.

\subsubsection{Isolated SC}

Fig. 7 shows the SAXS pattern of SC in the control skin and the skin treated with FFA bicellar systems. The pattern of the control skin shows a band centered at a $q$ around $1.05 \mathrm{~nm}^{-1}$, corresponding to a d value around $6 \mathrm{~nm}$. This d-spacing is associated with a lamellar arrangement of the lipids. When the skin was treated with the FFA bicellar systems, a shift of the position to lower $q$ (around $0.87 \mathrm{~nm}^{-1}$ ), corresponding to a d value of approximately $7.2 \mathrm{~nm}$, and an increase of the intensity were observed. Additionally, a small shoulder centered at a $q$ of approximately $1.26 \mathrm{~nm}^{-1}$ $(d \approx 5 \mathrm{~nm})$ appeared. These data suggest that the treatment with FFA bicellar systems induces some ordering in the SC lipid structure.

\section{Discussion}

Bicellar systems containing FFA have been characterized in a previous work (Rubio et al., 2011). These systems allow the inclusion of the lipophilic drug FFA without using organic solvents,
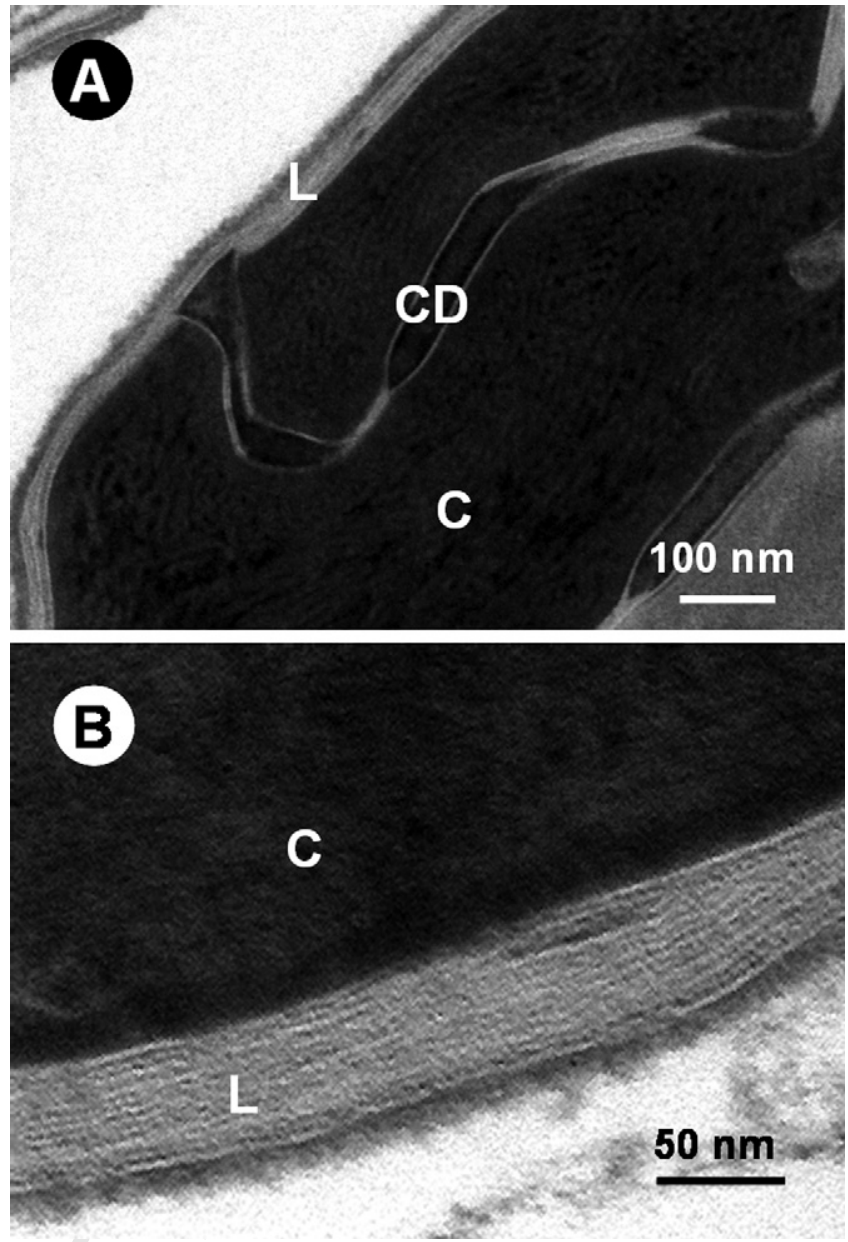

Fig. 4. FSTEM micrographs of SC from skin treated with FFA bicellar systems. Picture A: overview of the SC. Picture B: detailed micrograph of the lamellar structure. Symbols: corneocytes (C), corneodesmosomes (CD) and lipids (L).

and they exhibit great morphological versatility. The present work studied the potential of bicellar systems as a strategy to deliver drugs through the skin without damaging the tissue. We discuss the results from two different viewpoints: the effect of the bicellar system as retarder of the drug absorption and that of the bicellar system on the skin structure and functionality.

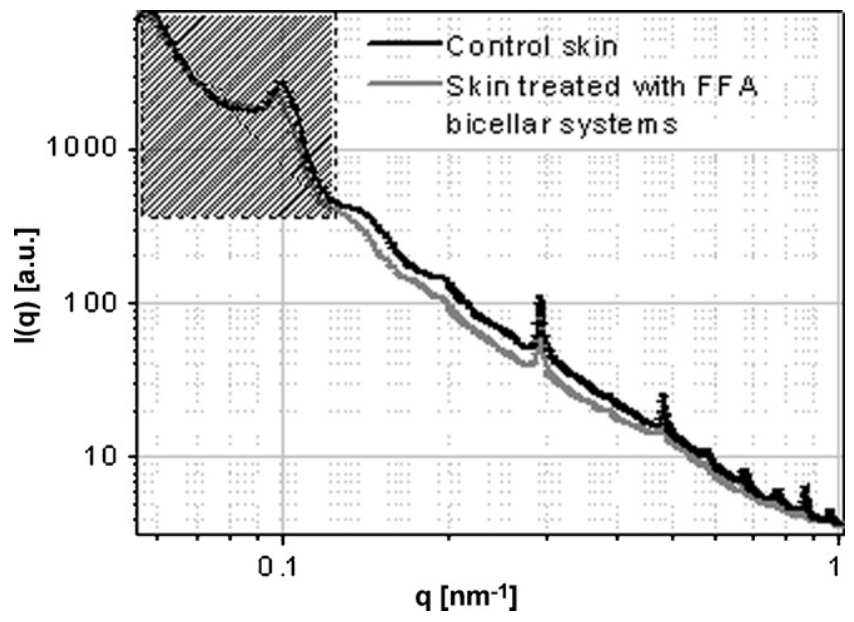

Fig. 5. SAXS intensity profile as a function of the scattering vector modulus $q$ of control skin and skin treated with FFA bicellar systems, plotted as scattering intensity. 
A

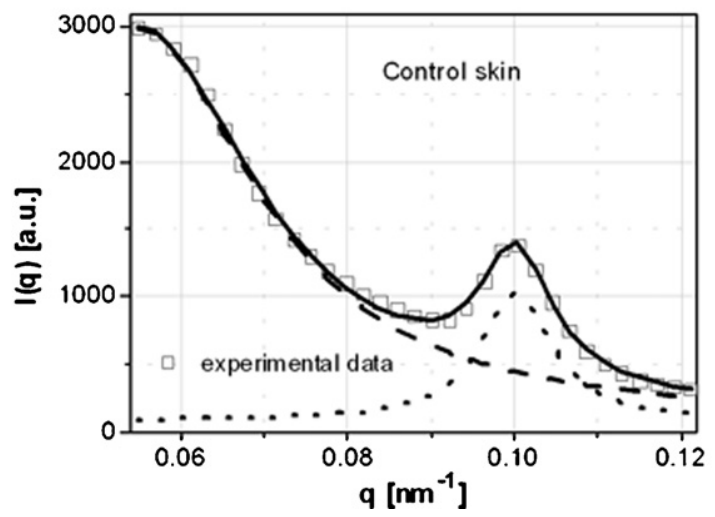

B

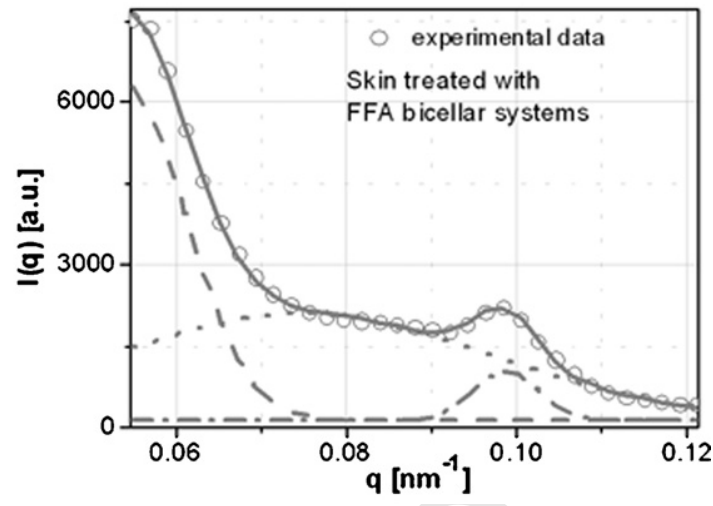

Fig. 6. Curve fitting analysis of the SAXS profile at low $q$ of the control skin (A) and skin treated with FFA bicellar systems (B).

\subsection{Bicellar systems retard FFA percutaneous absorption}

The results obtained for the percutaneous absorption of FFA in the different vehicles (considering all the skin layers) show the lowest value when the drug was included in bicellar system and the highest when FFA was dissolved in ethanol.

The values obtained for the ethanolic solution were probably due to the penetration-enhancing effect of this solvent (Thong et al., 2007). Merle et al. (Merle and Baillet-Guffroy, 2009) reported a reduction of SC thickness associated with the solubilization of the SC lipids by ethanol. This effect could enhance the permeability of the tissue. An enhancement in the permeability is associated in most cases with a fluidification of SC lipids that involves greater movement of the lipid alkyl chains in these areas (Williams and Barry, 2006). However, considering our ATR-FTIR results, this effect did not seem to occur in samples treated with the FFA ethanolic solution. The positions of the symmetric and asymmetric stretching bands of skin lipids after treatment with the FFA ethanolic solution showed a slight ordering rather than the expected disordering of the intercellular lipid alkyl chains with respect to the control skin. These results are in accordance with Bommannan et al. (1991), who found that while ethanol extracts appreciable amounts of lipids from the SC, it does not appear to induce lipid disordering. Our FTIR scissoring results indicate a shift of the characteristic HEX peak to lower values. This shift could be associated with the

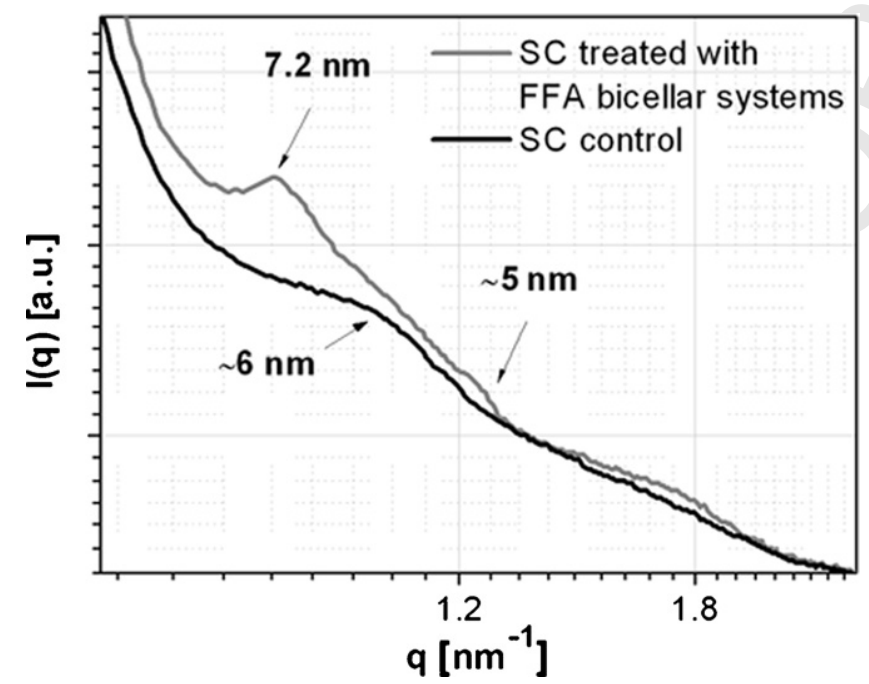

Fig. 7. SAXS profile at high $q$ of the SC of control skin and skin treated with FFA bicellar systems. extraction of some of the SC lipids. The change in the lipid composition would have induced a certain disturbance in the SC barrier function that manifested as an increase of skin permeability. The band that remained at $1465.7 \mathrm{~cm}^{-1}$ could have been related to the ceramides, which are more resistant to the ethanol extraction (Merle and Baillet-Guffroy, 2009). The results obtained corroborate our hypothesis that lipid extraction rather than disruption of lipid ordering is the predominant mechanism by which ethanol enhances skin permeability. Another, complementary explanation was suggested by Lewis et al. (1989), who claimed that the apparent ordering produced by ethanol treatment was due to an interdigitation effect of the lipid hydrocarbon chains by the displacement of bound water molecules at the lipid headgroup/membrane interface region. Additionally, our results reflect the effect of not only ethanol, but also FFA. The combined action of both components could lead to these effects on the SC lipids: an increase in the permeation of the skin together with an ordering in the lipid packing.

The percutaneous absorption of FFA in the commercial product was lower than when the drug was included in the ethanolic solution, although higher than in the case of FFA in bicellar systems. This was probably due to the composition of the commercial product, which, apart from FFA, consisted of $2 \%$ salicylic acid. This compound is a keratolytic molecule that can alter the barrier properties of the skin and provokes a desquamation of corneocytes that reduces the SC barrier function (Bashir et al., 2005; Dias et al., 2007; Lebwohl, 1999). Therefore, it could have enhanced the permeability of the SC. The ATR-FTIR results show an ordering of the SC lipids compared to the control when the commercial product was applied. This apparent ordering could have been due to alcoholic excipients of the commercial product, such as isopropanol and polypropylene glycol, that could extract some of the SC lipids and could induce similar effects on ATR-FTIR bands as ethanol did. In any case, the analysis of the effect of the commercial product is complicate due to the variety of compounds present in the formulation. The salicylic acid could damage the barrier function by a keratolitic effect whereas isopropanol and polypropylene glycol could affect the lipids.

When FFA was included in bicellar systems and applied to the skin, the total percutaneous absorption was the lowest of all three vehicles. In spite of this fact, the percentage of drug detected in dermis was very similar for samples treated with bicellar systems and the commercial product. This layer showed the lowest retention capacity of drug as it could be expected given dermis exhibits higher permeability than other layers. Fig. 1 shows the percentage absorbed after $24 \mathrm{~h}$ of exposure, although drug percentage in dermis is similar for FFA applied in bicellar systems and in the commercial product the amount in the receptor fluid is higher for the commercial gel. These results suggest a retardation of percutaneous absorption when the drug was included in bicellar systems. 
The concept of absorption retardation was described by Schaefer and co-workers (Schaefer and Redermeier, 1996) and is associated with agents that reduce the percutaneous absorption of compounds by augmenting skin barrier functions. Possibly, lipids from bicelles interact with the SC lipids, modifying the organization of the lipid bilayers and increasing the SC barrier function. This effect has also been described for compounds such as iminosulfurane (Asbill and Michniak, 2000; Kim et al., 1999) and laurocapram analogs N0915 (Asbill and Michniak, 2000; Hadgraft et al., 1996). The phospholipid dimyristoyl phosphatidylcholine (DMPC) was also described as retarder of the percutaneous absorption of the flurbiprofen in comparison to unsaturated fatty acids and cyclic monoterpenes, which acts as enhancers (Fang et al., 2003). The retardation effect of DMPC is associated with the higher gel-liquid phase transition temperature $\left(T_{\mathrm{m}}\right)$ of this phospholipid, $23^{\circ} \mathrm{C}$, respect to the other molecules used in this study. In the case of FFA bicellar systems, the $T_{\mathrm{m}}$ associated to DPPC is higher $\left(38.9^{\circ} \mathrm{C}\right.$ ) (Rubio et al., 2011) than that of DMPC. This fact involves that at the experimental temperature $\left(32^{\circ} \mathrm{C}\right)$, the bicellar systems applied are in the gel state. Gel-state phospholipids do not affect, or even increase, the skin lipid barrier (Fang et al., 2003; Kirjavainen et al., 1999), resulting, in our case, in a reduction of the drug permeation. The retardation effect of FFA bicellar systems is in accordance with our previous results in which diclofenac diethylamine was included in DPPC/DHPC bicellar systems (Rubio et al., 2010). This behavior is expected to be useful in the topical application of drugs that exhibit too fast percutaneous absorption rates, as is the case of fentanyl, to prevent an overdose of the drug (Frolich et al., 2001). The same occurs in the vehiculization of cosmetic ingredients that should not penetrate in large amounts or in dermatological formulations to be applied to skin with impaired barrier function because these formulations could prevent penetration into the circulation. This last topic is being currently studied in our laboratory.

\subsection{FFA bicellar systems do not disturb the SC lipid organization}

Images of SC from control skin and skin treated with FFA bicellar systems showed microstructures comparable to those published by other authors for native skin (López et al., 2001; Rodríguez et al., 2011). The well-organized lamellar lipid structure in both samples indicates that no structural modifications in the SC were induced by the FFA bicellar system treatment. The effect of different bicellar systems on the SC microstructure has been studied by our group. We reported that DMPC/DHPC bicelles do not promote changes in the organization of the SC lipid lamellae (Barbosa-Barros et al., 2008a, 2009), whereas DPPC/DHPC bicelles induce the formation of vesicles in the lipid areas (Barbosa-Barros et al., 2009; Rodríguez et al., 2011). This different behavior may be understood by considering the $T_{\mathrm{m}}$ associated with the long-alkyl-chain phospholipids of each system $\left(23^{\circ} \mathrm{C}\right.$ for DMPC and $41^{\circ} \mathrm{C}$ for DPPC). Another factor to be considered is the ability of bicellar systems to increase in size as the water content in the system increases (Barbosa-Barros et al., 2008b). When DMPC/DHPC bicelles are applied to the skin at physiological temperature $\left(37^{\circ} \mathrm{C}\right)$, this system suffers a phase transition from gel to a liquid crystalline state. This change induces an increase in the size of these structures that hinders the passage of the bicelles through the SC. In the case of DPPC/DHPC systems with higher $T_{\mathrm{m}}$, contact with the skin at $37^{\circ} \mathrm{C}$ does not promote the phase transition, and their size does not change, allowing their penetration through the SC. According to our experience, inside the skin, these bicelles grow as a consequence of a dilution caused by the water located in the skin (Barbosa-Barros et al., 2008b). In the present work, although FFA bicellar systems were composed of DPPC and DHPC, no changes in the SC lipid areas were detected. This was due to the fact that when DPPC/DHPC includes FFA, the size of the nanostructures and phase behavior of the system is modified. The new bicellar system with FFA forms larger aggregates than those detected in the system without FFA (Rubio et al., 2011). This could hinder their passage through the SC, and hence, no new lipid structures are visualized in the SC after treatment, as our FSTEM micrographs showed.

In spite of the absence of new lamellar or vesicular structures after treatment with FFA bicellar systems, a small effect in the lipid organization of the SC was detected. Thus, a partial diffusion of lipids and of FFA from bicellar systems into the SC occurred. Our ATR-FTIR and SAXS results show an ordering of the SC lipids compared to the control that agrees with the retardation effect on permeability described above. This increased order may have been induced by the inclusion of DPPC from the bicellar system into the lipid bilayers of the tissue. This phospholipid in a gel-ordered phase at the experimental temperature could promote additional ordering in the lamellar SC structure (Rodriguez et al., 2010). Additionally, in ATR-FTIR measurements for the stretching vibration, samples treated with bicellar systems showed the largest change against elevation of temperature. Considering that at $37^{\circ} \mathrm{C}$ the fluidity state of SC lipids (symmetric stretching band, Table 1 ) is very similar in all the samples, this result could be related to the increase in the SC lipid organization at $25^{\circ} \mathrm{C}$ after the treatment with bicellar system. The ordering increase would be promoted by the interaction of lipids from bicelles with lipids from SC as was published by Rodriguez et al. (2010). SAXS experiments performed in SC samples (control and treated with FFA bicellar systems) showed increased d-spacing for the short periodicity phase (SPP) of the SC lamellar phases reported by Bouwstra et al. (Bouwstra et al., 1991). The dspacing is the sum of the lipid bilayer thickness and the thickness of one adjacent interlamellar water layer (de Jager et al., 2005). For this reason, the increase of the d-spacing when the SC was treated with FFA bicellar systems could have been promoted by the incorporation of water on lamellae or the incorporation of lipids in the gel phase. The increased d-spacing corroborates the interaction of bicelles with SC lipids. The higher intensity of the SPP band in the case of the treated SC compared to the control indicates an increase of the ordering of the SC lipid structure. In any case, no extraction of SC lipids should be expected after treatment with the bicellar systems; on the contrary, an enrichment of these areas could be envisaged, and considering the results from percutaneous absorption, a reinforcement of the SC barrier function seems likely.

Our results indicate that the use of bicellar systems allows for small amounts of an anti-inflammatory drug to be incorporated in the skin without disturbing the tissue. Skin barrier disruption causes chronic inflammation (Rahman et al., 2011). Because of this, it is crucial to adjust treatment to avoid skin barrier disruption. In this sense, anti-inflammatory drugs should be used with vehicles that avoid skin damage. Our results should help skin care researchers improve the SC barrier function to prevent and reverse the skin damage that is caused by and causes chronic inflammation. The use of bicellar systems as vehicles, in spite of reducing the amount of anti-inflammatory drug absorbed, could be effective in treating skin inflammation by improving skin structure and functionality. Future in vivo research should explore the potential of this strategy.

\section{Conclusions}

Ethanol as a vehicle and the variety of components contained in a commercial product alter the skin barrier function in different ways: as a lipid-solubilizing or a keratolytic agent. In contrast, bicellar systems did not disturb the SC barrier function but seemed to prevent and reinforce skin microstructure and functionality. The results of our work may be useful to develop bicellar systems as alternative vehicles for drugs that need to be solubilized by organic solvents and that have a very fast percutaneous absorption. These 
drugs could be applied to the skin without the danger of potential toxicity or of delirious effects on the skin structure.

\section{Acknowledgments}

The authors acknowledge the Ministerio de Educación y Ciencia, Spain (CTQ2010-16964) and Generalitat de Catalunya (2009 SGR 1212). This work was supported by the European Social Fund (Programa Nacional de Potenciación de Recursos Humanos del Plan Nacional de I+D+I (2004-2008)). Mercedes Cócera is funded by the JAE-Doc Program from CSIC (co-funded by FSE). Additionally, the authors wish to thank Elisenda Coll for her expert technical assistance.

\section{References}

Asbill, C.S., Michniak, B.B., 2000. Percutaneous penetration enhancers: local versus transdermal activity. PSTT 3, 36-41.

Bal, S.M., Ding, Z., van Riet, E., Jiskoot, W., Bouwstra, J.A., 2010. Advances in transcutaneous vaccine delivery: do all ways lead to Rome. J. Control. Release 148, 266-282.

Barbosa-Barros, L., Barba, C., Cócera, M., Coderch, L., López-Iglesias, C., de la Maza, A., López, O., 2008a. Effect of bicellar systems on skin properties. Int. J. Pharm. $352,263-272$.

Barbosa-Barros, L., Barba, C., Rodríguez, G., Cócera, M., Coderch, L., López-Iglesias, C., de la Maza, A., López, O., 2009. Lipid nanostructures: self-assembly and effect on skin properties. Mol. Pharm. 6, 1237-1245.

Barbosa-Barros, L., de la Maza, A., Estelrich, J., Linares, A.M., Feliz, M., Walther, P. Pons, R., López, O., 2008b. Penetration and growth of DPPC/DHPC bicelles inside the stratum corneum of the skin. Langmuir 24, 5700-5706.

Barbosa-Barros, L., De la Maza, A., Walther, P., Estelrich, J., López, O., 2008c. Morphological effects of ceramide on DMPC/DHPC bicelles. J. Microsc. 230, 16-26.

Bashir, S.J., Dreher, F., Chew, A.L., Zhai, H., Levin, C., Stern, R., Maibach, H.I., 2005. Cutaneous bioassay of salicylic acid as a keratolytic. Int. J. Pharm. 292, 187-194.

Bommannan, D., Potts, R.O., Guy, R.H., 1991. Examination of the effect of ethanol on human stratum corneum in vivo using infrared spectroscopy. J. Control. Release 16, 299-304.

Boncheva, M., Damien, F., Normand, V., 2008. Molecular organization of the lipid matrix in intact Stratum corneum using ATR-FTIR spectroscopy. Biochim. Biophys. Acta $1778,1344-1355$

Bouwstra, J.A., Gooris, G.S., van der Spek, J.A., Bras, W., 1991. Structural investigations of human stratum corneum by small-angle X-ray scattering. J. Invest. Dermatol. 97, 1005-1012.

Bragg, W.L., 1913. The diffraction of short electromagnetic waves by a crystal. Proceedings of the Cambridge Philosophical Society, 43-57.

Cócera, M., Rodríguez, G., Rubio, L., Barbosa-Barros, L., Benseny-Cases, N., Cladera, J., Sabes, M., Fauth, F., de la Maza, A., López, O., 2011. Characterisation of skin states by non-crystalline diffraction. Soft Matter 7, 8605-8611.

Coderch, L., de Pera, M., Perez-Cullell, N., Estelrich, J., de la Maza, A., Parra, J.L., 1999. The effect of liposomes on skin barrier structure. Skin Pharmacol. Appl. Skin Physiol. 12, 235-246.

de Jager, M.W., Gooris, G.S., Ponec, M., Bouwstra, J.A., 2005. Lipid mixtures prepared with well-defined synthetic ceramides closely mimic the unique stratum corneum lipid phase behavior. J. Lipid Res. 46, 2649-2656.

Dias, M., Hadgraft, J., Lane, M.E., 2007. Influence of membrane-solvent-solute interactions on solute permeation in skin. Int. J. Pharm. 340, 65-70.

Elias, P.M., Feingold, K.R., 2006. Skin Barrier. Taylor and Francis group, New york.

Fang, J.Y., Hwang, T.L., Leu, Y.L., 2003. Effect of enhancers and retarders on percutaneous absorption of flurbiprofen from hydrogels. Int. J. Pharm. 250, 313-325.

Frolich, M.A., Giannotti, A., Modell, J.H., 2001. Opioid overdose in a patient using a fentanyl patch during treatment with a warming blanket. Anesth. Analg. 93, 647-648.

Furuishi, T., Fukami, T., Suzuki, T., Takayama, K., Tomono, K., 2010. Synergistic effect of isopropyl myristate and glyceryl monocaprylate on the skin permeation of pentazocine. Biol. Pharm. Bull. 33, 294-300.

Gooris, G.S., Bouwstra, J.A., 2007. Infrared spectroscopic study of stratum corneum model membranes prepared from human ceramides, cholesterol, and fatty acids. Biophys. J. 92, 2785-2795.

Gwak, H.S., Chun, I.K., 2002. Effect of vehicles and penetration enhancers on the in vitro percutaneous absorption of tenoxicam through hairless mouse skin. Int. J. Pharm. 236, 57-64.

Hadgraft, J., Peck, J., Willians, D.G., Pugh, W.J., Allan, G., 1996. Mechanisms of action of skin penetration enhancers/retarders: Azone and analogues. Int. J. Pharm. 141, 17-25.

Kaushik, D., Michniak-Kohn, B., 2010. Percutaneous penetration modifiers and formulation effects: thermal and spectral analyses. AAPS PharmSciTech 11, 1068-1083.

Kim, N., El-Khalili, M., Henary, M.M., Strekowski, L., Michniak, B.B., 1999. Percutaneous penetration enhancement activity of aromatic S,Sdimethyliminosulfuranes. Int. J. Pharm. 187, 219-229.
Kirjavainen, M., Monkkonen, J., Saukkosaari, M., Valjakka-Koskela, R., Kiesvaara, J. Urtti, A., 1999. Phospholipids affect stratum corneum lipid bilayer fluidity and drug partitioning into the bilayers. J. Control. Release 58, 207-214.

Lebwohl, M., 1999. The role of salicylic acid in the treatment of psoriasis. Int. J. Dermatol. 38, 16-24.

Lewis, E.N., Levin, I.W., Steer, C.J., 1989. Infrared spectroscopic study of ethanolinduced changes in rat liver plasma membrane. Biochim. Biophys. Acta 986 $161-166$.

López, O., Cócera, M., Walther, P., Wehrli, E., Coderch, L., Parra, J.L., de la Maza, A. 2001. Liposomes as protective agents of stratum corneum against octyl glucoside: a study based on high-resolution, low-temperature scanning electron microscopy. Micron 32, 201-205.

Mendelsohn, R., Flach, C.R., Moore, D.J., 2006. Determination of molecular conformation and permeation in skin via IR spectroscopy, microscopy, and imaging. Biochim. Biophys. Acta 1758, 923-933.

Mérigoux, C., Durand, D., Doucet, J., Eugéne, M., Diat, O., 1997. Supramolecular organisation of collagen fibrils in human tissues. Newsl. ESRF, 18-19.

Merle, C., Baillet-Guffroy, A., 2009. Physical and chemical perturbations of the supramolecular organization of the stratum corneum lipids: in vitro to ex vivo study. Biochim. Biophys. Acta 1788, 1092-1098.

Obata, Y., Utsumi, S., Watanabe, H., Suda, M., Tokudome, Y., Otsuka, M., Takayama, K., 2010. Infrared spectroscopic study of lipid interaction in stratum corneum treated with transdermal absorption enhancers. Int. J. Pharm. 389, 18-23.

OECD, 2004. Guideline 428: skin absorption: in vitro method. In: OECD (Ed.), OECD Q Guidelines for the Testing of Chemicals. Paris, p. 8.

Parra, J.L., Paye, M., 2003. EEMCO guidance for the in vivo assessment of skin surface pH. Skin Pharmacol. Appl. Skin Physiol. 16, 188-202.

Pensack, R.D., Michniak, B.B., Moore, D.J., Mendelsohn, R., 2006. Infrared kinetic/structural studies of barrier reformation in intact stratum corneum following thermal perturbation. Appl. Spectrosc. 60, 1399-1404.

Prasch, T., Knubel, G., Schmidt-Fonk, K., Ortanderl, S., Nieveler, S., Forster, T., 2000 Infrared spectroscopy of the skin: influencing the stratum corneum with cosmetic products. Int. J. Cosmet. Sci. 22, 371-383.

Prausnitz, M.R., Mitragotri, S., Langer, R., 2004. Current status and future potentia of transdermal drug delivery. Nat. Rev. Drug Discov. 3, 115-124.

Rahman, S., Collins, M., Williams, C.M., Ma, H.L., 2011. The pathology and immunology of atopic dermatitis. Inflamm. Allergy Drug Targets 10, 486-496.

Rodríguez, G., Barbosa-Barros, L., Rubio, L., Cócera, M., Díez, A., Estelrich, J., Pons, R. Caelles, J., De la Maza, A., López, O., 2009. Conformational changes in stratum corneum lipids by effect of bicellar systems. Langmuir 25, 10595-10603.

Rodríguez, G., Barbosa-Barros, L., Rubio, L., Cócera, M., López-Iglesias, C., de la Maza A., López, O., 2011. Bicellar systems as modifiers of skin lipid structure. Colloids Surf. B: Biointerfaces 84, 390-394.

Rodriguez, G., Rubio, L., Cocera, M., Estelrich, J., Pons, R., de la Maza, A., Lopez, O., 2010. Application of bicellar systems on skin: diffusion and molecular organization effects. Langmuir 26, 10578-10584.

Rubio, L., Alonso, C., Rodríguez, G., Barbosa-Barros, L., Coderch, L., De la Maza, A., Parra, J.L., López, O., 2010. Bicellar systems for in vitro percutaneous absorption of diclofenac. Int. J. Pharm. 386, 108-113.

Rubio, L., Rodríguez, G., Alonso, C., López-Iglesias, C., Cócera, M., Coderch, L., De la Maza, A., Parra, J.L., López, O., 2011. Structural effects of flufenamic acid in DPPC/DHPC bicellar systems. Soft Matter 7, 8488-8497.

Rueda, D.R., García-Gutiérrez, M.C., Nogales, A., Capitán, M.J., Ezquerra, T.A Labrador, A., Fraga, E., Beltrán, D., Juanhuix, J., Herranz, J.F., Bordas, J., 2006. Versatile wide angle diffraction setup for simultaneous wide and small angle X-ray scattering measurements with synchrotron radiation. Rev. Sci. Instrum. 77, 033901-033905.

Sanders, C.R., Prosser, R.S., 1998. Bicelles: a model membrane system for all seasons? Structure 6, 1227-1234

Sanders, C.R., Schwonek, J.P., 1992. Characterization of magnetically orientable bilayers in mixtures of dihexanoylphosphatidylcholine and dimyristoylphosphatidylcholine by solid-state NMR. Biochemistry 31, 8898-8905.

Schacke, H., Docke, W.D., Asadullah, K., 2002. Mechanisms involved in the side effects of glucocorticoids. Pharmacol. Ther. 96, 23-43.

Schaefer, H., Redermeier, T.E., 1996. Skin Barrier-Principles of Percutaneous absorption. Karger-Verlag, Basel.

Seddon, A.M., Curnow, P., Booth, P.J., 2004. Membrane proteins, lipids and detergents: not just a soap opera. Biochim. Biophys. Acta 1666, 105-117.

Thomas, B.J., Finnin, B.C., 2004. The transdermal revolution. Drug Discov. Today 9 697-703.

Thong, H.Y., Zhai, H., Maibach, H.I., 2007. Percutaneous penetration enhancers: an overview. Skin Pharmacol. Physiol. 20, 272-282.

Van den Bergh, B.A., Swartzendruber, D.C., Bos-Van der Geest, A., Hoogstraate, J.J., Schrijvers, A.H., Boddé, H.E., Junginger, H.E., Bouwstra, J.A., 1997. Development of an optimal protocol for the ultrastructural examination of skin by transmission electron microscopy. J. Microsc. 187, 125-133.

Vold, R.R., Prosser, R.S., 1996. Magnetically oriented phospholipid bilayered micelles for structural studies of polypeptides. Does the ideal bicelle exist? J. Magn. Reson. Ser. B 113, 267-271.

Wagner, H., Kostka, K.H., Adelhardt, W., Schaefer, U.F., 2004. Effects of various vehicles on the penetration of flufenamic acid into human skin. Eur. J. Pharm. Biopharm. 58, 121-129.

Williams, A.C., Barry, B.W., 2006. Chemical permeation enhancement. In: Touitou, E., Barry, B.W. (Eds.), Enhancement in Drug Delivery. CRC Press.
860

861

862

864 